\title{
Testicular sperm retrieval and intra cytoplasmic sperm injection provide favorable outcome in spinal cord injury patients, failing conservative reproductive treatment
}

\author{
G Raviv, I Madgar, S Elizur, G Zeilig and J Levron
}

Study design: Retrospective cohort analysis.

Objectives: The objective of this study was to determine the in vitro fertilization (IVF) outcome after testicular sperm extraction (TESE) in a group of spinal cord injury (SCI) male patients not compatible with conservative fertility treatment.

Setting: University-affiliated medical center.

Methods: Thirty two SCI patients (C2 to L2) were referred to IVF after repeated trials of electroejaculation (EEJ) or penile vibratory stimulation (PVS), and full andrological evaluation. Testicular sperm aspiration (TESA) was the method of choice for sperm extraction. Open TESE was performed only after a negative TESA attempt. Clinical pregnancy and live birth rates were determined.

Results: A total of 106 testicular procedures were performed. Sperm was found in 95 cycles (89.6\%). The average metaphase II (MII) oocyte number was $11.0 \pm 4.2$, an average of $5.1 \pm 2.3$ oocytes became normally fertilized after Intra Cytoplasmic Sperm Injection (ICSI) (fertilization rate $57.1 \%$ ). On average, $2.7 \pm 1.2$ embryos were replaced. The clinical pregnancy rate was 32/106 (30.2\%) per cycle and 19/32 (59.3\%) per couple. Live birth rate was 62.5\% (20/32).

Conclusions: TESA/E and IVF can provide excellent prognosis for SCI patients that cannot be treated by EEJ or PVS.

Spinal Cord (2013) 51, 642-644; doi:10.1038/sc.2013.44; published online 21 May 2013

Keywords: spinal cord injury; testicular sperm extraction; in vitro fertilization

\section{INTRODUCTION}

Spinal cord injuries (SCI) are more common in younger patients and usually happen due to accidents or combat injuries. At some point after their long rehabilitation process, these patients may seek for reproductive therapy.

Infertility is a common and a frustrating problem for many men after SCI. ${ }^{1}$ Most of them suffer from infertility, mainly due to erectile and/or ejaculatory dysfunction., ${ }^{2,3}$

Antegrade ejaculation has been reported in 5\% of patients with complete upper motor neuron lesions, $18 \%$ with complete lower motor neuron lesions and $32 \%$ with incomplete upper motor neuron lesions and $70 \%$ with incomplete lower motor neuron lesions.

For those who do not have the possibility to ejaculate, penile vibratory stimulation (PVS) and/or electroejaculation (EEJ) in conjunction with intrauterine insemination, or in vitro fertilization (IVF) seem to be promising with different percentage of pregnancies. ${ }^{4-9}$

In our previous study, by using EEJ combined with assisted reproductive technique (ART), we showed high percentage of pregnancies despite the typically poor sperm motility. ${ }^{10}$

In cases where azoospermia was evident during initial evaluation, the only option to conceive was to perform testicular biopsy for sperm retrieval and IVF. In the present study, we have summarized the IVF outcome in a group of such azoospermic SCI patients.

\begin{abstract}
MATERIALS AND METHODS
During the period between 1996 and May 2012, 152 patients were evaluated and treated in our center. Out of this group, a total of 32 SCI patients were found to be aspermic. After workup, they were diagnosed either as obstructive azoospermia (group-I), non-obstructive azoospermia (group-II) or with severe oligozoospermia (group-III), unsuitable for intrauterine insemination (total motile count $<5 \times 10^{6}$ ). These patients were referred to IVF treatment after repeated trials of PVS or EEJ. PVS was used as a first line of treatment in all patients with lesions above T10. SCI patients with lower level of injury or patients who failed PVS treatment were treated by EEJ (Figure 1).
\end{abstract}

The spinal lesions extended from $\mathrm{C} 2$ to $\mathrm{L} 2$

All patients were in a stable medical state and were anejaculatory since their injury. The baseline laboratory evaluations included physical examination, testicular volume determination by Prader orchydometer, blood biochemistry, complete blood count, follicle-stimulating hormone (FSH), luteinizing hormone (LH), testosterone and prolactin levels. All male partners with elevated serum FSH levels were karyotyped. Testicular ultrasound was done in patients who had abnormal physical examination or history of recurrent episodes of epididymitis. Subjects with a urinary tract infection were treated with antibiotics prior surgery.

Azoospermia was documented by multiple emitted specimens obtained by EEJ followed by bladder catheterization. Both samples were processed by centrifugation and subsequent careful examination of the resuspended pellet. A small group of seven patients that were referred to IVF due to poor sperm

IVF and Andrology Units, Urology and Rehabilitation Department, The Chaim Sheba Medical Center (affiliated to Sackler School of Medicine, Tel Aviv University, Tel Aviv), Tel Hashomer, Israel

Correspondence: Dr G Raviv, IVF and Andrology Units, Urology and Rehabilitation Department, The Chaim Sheba Medical Center (affiliated to Sackler School of Medicine, Tel Aviv University, Tel Aviv), Tel Hashomer 52621, Israel.

E-mail: gravivg@zahav.net.il

Received 11 November 2012; revised 21 March 2013; accepted 4 April 2013; published online 21 May 2013 


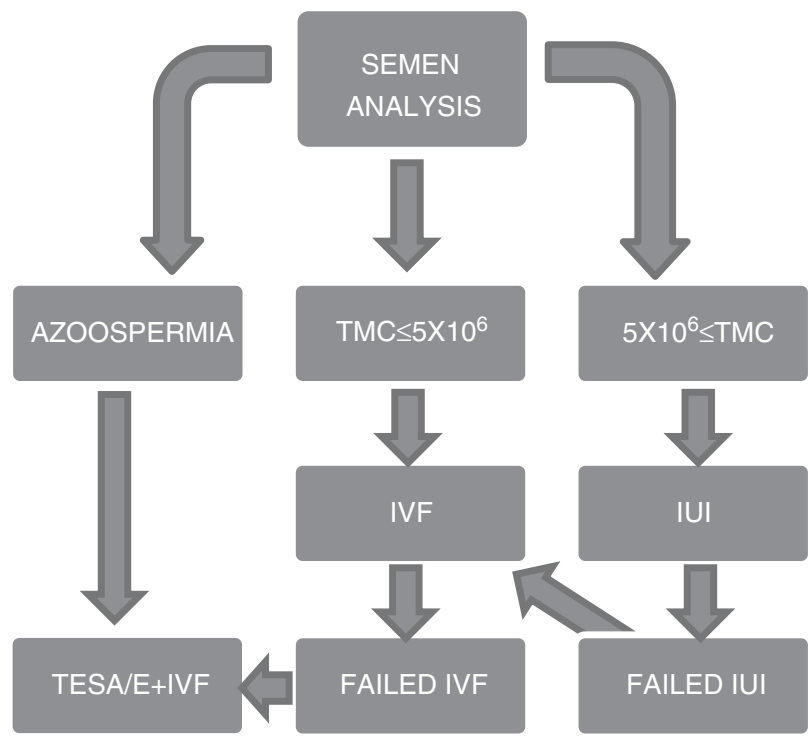

Figure $1 \mathrm{SCl}$ infertility treatment model.

quality after EEJ were included in the study, as testicular sperm aspiration (TESA) was indicated after fertilization failure or very low fertilization rates.

Testicular sperm were obtained by TESA as a method of choice. The tissue was processed immediately after biopsy and was assessed by X200 power-field microscopy for the presence of mature spermatozoa and motility. The operation was terminated once sperm was found. In case of negative result, the opposite testicle was operated. When repeated biopsies were attempted, the operation was scheduled after at least 3 months and the alternate testicle was biopsied. In cases where no sperm was found by TESA, open testicular sperm extraction (TESE) was performed. In such cases, part of the testicular tissue was used for histological examination. The preparation of the testicular tissue for IVF was described elsewhere. ${ }^{11}$ All the procedures were carried out under the authorization of the local IRB committee.

\section{RESULTS}

Thirty two couples were included in this study. The mean age of the male partner was $38 \pm 5.57$ years (range 26-47). The mean age of the female partners was $34.5 \pm 4.66$ years (range 26-44). The mean age at injury of the male partners was $21.7 \pm 4.3$ years and the average interval till the ART procedure was carried out was $7.6 \pm 2.1$ years (range 5-16).

At the time of their reproductive evaluation 6 out of the 32 patients (18.7\%) have been found to be azoospermic, with elevated serum FSH levels (mean $16.8 \pm 3.3 \mathrm{mIU} \mathrm{ml}^{-1}$ ) due to primary testicular failure. Seven patients had sperm in their ejaculates after EEJ; however, eventually, due to poor sperm quality or low fertilization rates and repeated implantation failures, they underwent surgery. In the rest 19 patients, sperm was not found after repeated EEJ procedures and they were referred directly to surgery. All the patients with primary testicular failure had normal karyotype. All the other patients had normal levels of FSH, LH, serum testosterone and prolactin levels. The average right and left testicular volumes were $22 \pm 2.85$ and $21 \pm 4.72 \mathrm{ml}$, respectively.

In all six azoospermic patients with elevated serum FSH levels, tissue was evaluated after testicular biopsy (TESE) for histology, revealing picture of sertoli cell only tubules. In this group, sperm was found in four patients with serum FSH levels $<20 \mathrm{mIUml}^{-1}$. In the other two patients with serum FSH levels higher than this cutoff limit, sperm was not found in the testicle.
Table 1 Patients subgroup characteristics

\begin{tabular}{|c|c|c|c|}
\hline Patient group & $\begin{array}{l}\text { 1. Obstructive } \\
\text { azoospermia } \\
(\mathrm{n}=19)\end{array}$ & $\begin{array}{c}\text { II. Non- } \\
\text { obstructive } \\
\text { azoospermia } \\
(\mathrm{n}=6)\end{array}$ & $\begin{array}{c}\text { III. Severe } \\
\text { oligozoosper- } \\
\text { mia }(n=7)\end{array}$ \\
\hline $\begin{array}{l}\text { Average male age (years) } \\
\text { Average female age }\end{array}$ & $\begin{array}{c}38 \pm 5.7 \\
34.5 \pm 4.9\end{array}$ & $\begin{array}{c}34 \pm 7.5 \\
34.1 \pm 4.2\end{array}$ & $\begin{array}{l}35.0 \pm 4.7 \\
33.4 \pm 5.1\end{array}$ \\
\hline $\begin{array}{l}\text { (years) } \\
\text { Mean FSH (mlU ml-1; } \\
\text { range) }\end{array}$ & $9.5 \pm 2.1(0.7-11.1)$ & $18.0 \pm 14.1$ & $6.0 \pm 4.2$ \\
\hline $\begin{array}{l}\text { Mean LH (mlU ml-1; } \\
\text { range) }\end{array}$ & $6.0 \pm 7.6(0.8-7.6)$ & $15.2 \pm 19.1$ & $4.0 \pm 2.8$ \\
\hline $\begin{array}{l}\text { Mean testosterone } \\
\text { (ng ml-1; range) }\end{array}$ & $15.3 \pm 5.9(8.5-55)$ & $15.3 \pm 5.8$ & $18.3 \pm 9.0$ \\
\hline $\begin{array}{l}\text { Mean volume, } \\
\text { left testis (cc) }\end{array}$ & $20 \pm 4.9$ & $20.0 \pm 5.5$ & $21.0 \pm 4.6$ \\
\hline $\begin{array}{l}\text { Mean volume, } \\
\text { right testis (cc) }\end{array}$ & $21 \pm 2.4$ & $20.0 \pm 2.0$ & $22 \pm 3.7$ \\
\hline $\begin{array}{l}\text { Sperm retrieval rate } \\
\text { Birth rate (per couple) }\end{array}$ & $\begin{array}{l}19 / 19 \\
12 / 19^{a}\end{array}$ & $\begin{array}{l}4 / 6 \\
0 / 6^{b}\end{array}$ & $\begin{array}{l}7 / 7 \\
4 / 7^{a}\end{array}$ \\
\hline
\end{tabular}

Abbreviations: FSH, follicle-stimulating hormone; LH, luteinizing hormone.

aTwo couples delivered twice.

bTwo miscarriages.

A total of 106 testicular procedures were done on 32 patients. The average number of procedures was $3.3 \pm 2.9$ with a range of 1-13 procedures. The interval between TESA procedures was not less than 12 weeks. Sperm was found in 95 cycles (89.6\%). In the subgroup of patients with primary testicular failure, sperm was found only in four patients; however, none of the female partners became pregnant.

Following IVF procedure, the average metaphase-II oocyte number was $11.0 \pm 4.2$, an average of $5.1 \pm 2.3$ oocytes became normally fertilized after ICSI (fertilization rate 57.1\%). On average, $2.7 \pm 1.2$ embryos were transferred. Thirty two clinical pregnancies were established. The clinical pregnancy rate was 32/106 (30.2\%) per cycle and $19 / 32$ (59.3\%) per couple. Live birth rate was $62.5 \%(20 / 32)$. In the subgroup of seven couples that had sperm in their ejaculates four couples became pregnant and had live births (Table 1).

\section{DISCUSSION}

All patients with SCI suffer from various degrees of infertility due to erectile and ejaculatory dysfunctions. It has been demonstrated that the general rehabilitation process is more effective when attention is given to sexual function and infertility. ${ }^{3}$

PVS is used as a first line of treatment, as it is more physiological with better semen quality. ${ }^{4,5}$ In most patients with lesions above T10, semen may be produced effectively by PVS. SCI patients with lower level of injury may fail PVS treatment and are candidates for EEJ.

Most of the SCI patients have normal sperm counts with abnormal motility. Recent studies shows that these changes are due to accessory gland dysfunction and altered semen constituents due to stasis of prostatic fluid, testicular hyperthermia, recurrent urinary tract infections, abnormal testicular histology, hypothalamic-pituitary-testicular axis changes, sperm antibodies, chronic long-term use of various medications and bladder dysfunction. ${ }^{1-3,6,12-14}$ In addition, the EEJ procedure may further hamper sperm quality by the electroporation injuries. ${ }^{14-16}$ Other SCI patients may also suffer from either primary testicular failure or obstructive azoospermia. Such patients will be eventually referred to as ART treatments in order to conceive.

Our study and other's reports using EEJ show that semen analysis after this procedure shows large inter subject variations in sperm concentration, motility and morphology. ${ }^{2,6,7,17}$ In the present study, sperm quality was determined after repeated EEJ attempts, therefore, 
these 32 patients represent a group of SCI patients with poor reproductive prognosis.

Quite often inappropriate management and treatments such as delayed treatment of accessory gland infections or repeated traumatic self-catheterizations may lead to either testicular failure or obstruction. In the present study, over $50 \%$ of the patients had obstructive azoospermia and about 25\% (six patients) had primary testicular failure. It appears that this group of six patients demonstrated the poorest outcome, despite the fact that in four patients, sperm was present in the testicular tissue. Sperm was not found in two patients with a relatively high FSH levels. The prognosis in this group of patients with non-obstructive azoospermia is known to be less favorable than other male factor patients. ${ }^{18}$ The reasons are many folds and probably results from impaired maturation process and increased rate of aneuploidies. ${ }^{11}$

Our study, among other recent studies, ${ }^{9,19}$ demonstrates that ART can provide today excellent prognosis for SCI patients that cannot benefit from more conservative infertility management. Moreover, such patients may undergo TESA safely every 3 months without significant testicular damage. ${ }^{20}$ Overall $60 \%$ of the entire patient group achieved a live birth. ${ }^{21}$ The rate is even higher than $70 \%$ by excluding the group of patients with primary testicular failure. This group of patients needs probably more treatment cycles in order to succeed.

\section{DATA ARCHIVING}

There were no data to deposit.

\section{CONFLICT OF INTEREST}

The authors declare no conflict of interest.

1 DeForge D, Blackmer J, Garritty C, Yazdi F, Cronin V, Barrowman N et al. Fertility following spinal cord injury: a systematic review. Spinal Cord 2005; 43: 693-703.

2 Kafetsoulis A, Brackett NL, Ibrahim E, Attia GR, Lynne CM. Current trends in the treatment of infertility in men with spinal cord injury. Fertil Steril 2006; 86: 781-789.
3 Utida C, Truzzi JC, Bruschini H, Simonetti R, Cedenho AP, Srougi M et al. Male infertility in spinal cord trauma. Int Braz J Urol 2005; 31: 375-383.

4 Nehra A, Werner MA, Bastuba M, Title C, Oates RD. Vibratory stimulation and rectal probe electroejaculation as therapy for patients with spinal cord injury: semen parameters and pregnancy rates. J Urol 1996; 155: 554-559.

5 Ohl DA, Sønksen J, Menge AC, McCabe M, Keller LM. Electroejaculation versus vibratory stimulation in spinal cord injured men: sperm quality and patient preference. J Urol 1997; 157: 2147-2149

6 Chung PH, Yeko TR, Mayer JC, Sanford EJ, Maroulis GB. Assisted fertility using electroejaculation in men with spinal cord injury - a review of literature. Fertil Steril 1995; 64: 1-9.

7 Buch JP, Zorn BH. Evaluation and treatment of infertility in spinal cord injured men through rectal probe electroejaculation. J Urol 1993; 149: 1350-1354.

8 Chung PH, Verkauf BS, Eichberg RD, Casady L, Sanford EJ, Maroulis GB. Electroejaculation and assisted reproductive techniques for anejaculatory infertility. Obstet Gynecol 1996; 87: 22-26.

9 Leduc BE. Treatment of infertility in 31 men with spinal cord injury. Can J Urol 2012 19: 6432-6436.

10 Heruti RJ, Katz H, Menashe Y, Weissenberg R, Raviv G, Madjar I et al. Treatment of male infertility due to spinal cord injury using rectal probe electroejaculation: the Israeli experience. Spinal Cord 2001; 39: 168-175.

11 Levron J, Aviram-Goldring A, Madgar I, Raviv G, Barkai G, Dor J. Studies on sperm chromosomes in patients with severe male factor infertility undergoing assisted reproductive technology treatment. Mol Cell Endocrinol 2001; 183 (Suppl 1), S23-S28.

12 Ohl DA, Denil J, Fitzgerald-Shelton K, McCabe M, McGuire EJ, Menge AC et al. Fertility of spinal cord injured males: effect of genitourinary infection and bladder management on results of electroejaculation. J Am Parapleg Soc 1992; 15: 53-59.

13 Siosteen A, Steen Y, Forssman L, Sullivan L. Auto-immunity to spermatozoa and quality of semen in men with spinal cord injury. Int J Fertil 1993; 38: 117-122.

14 Brackett NL, Lynne CM, Ibrahim E, Ohl DA, Sønksen J. Treatment of infertility in men with spinal cord injury. Nat Rev Urol 2010; 7: 162-172.

15 Denil J, OhI DA, Menge AC, Keller LM, McCabe M. Functional characteristics of sperm obtained by electroejaculation. J Urol 1992; 147: 69-72.

16 Sarkarati M, Rossier AB, Fam BA. Experience in vibratory and electro-ejaculation techniques in spinal cord injury patients: a preliminary report. J Urol 1987; 138: 59-62.

17 Ohl DA, Bennett CJ, McCabe M, Menge AC, McGuire EJ. Predictors of success in electroejaculation of spinal cord injured men. J Urol 1993; 149: 1350-1354.

18 Demir B, Arikan II, Bozdag G, Esinler I, Karakoc Sokmensuer L, Gunalp S. ICSI outcome of patients with severe oligospermia vs. non-obstructive azoospermia. Clin Exp Obstet Gynecol 2012; 39: 141-143.

19 Kathiresan AS, Ibrahim E, Aballa TC, Attia GR, Ory SJ, Hoffman DI et al. Comparison of in vitro fertilization/intracytoplasmic sperm injection outcomes in male factor infertility patients with and without spinal cord injuries. Fertil Steril 2011; 96 562-566.

20 Raviv G, Levron J, Menashe Y, Bider D, Dor J, Ramon J et al. Sonographic evidence of minimal and short-term testicular damage after testicular sperm aspiration procedures. Fertil Steril 2004; 82: 442-444.

21 Levron J, Madgar I, Shefi S, Meirow D, Wiser A, Bider D et al. IVF outcome with cryopreserved testicular sperm. Andrologia 2011; 43: 48-51. 